\title{
ULTRA-WIDEBAND SYSTEMS WITH ORTHOGONAL CODED DIFFERENTIAL TR RECEIVER
}

\author{
Josip Milanović, Snježana Rimac-Drlje, Slavko Rupčić
}

Original scientific paper

This paper presents coded differential TR (cDTR) receiver that transmits extra bit by mapping information in $K$ different orthogonal codes. The performance of the coded DTR is analyzed and compared with the conventional DTR. Throughout the analysis, the performance of receivers in terms of bit error probability (BEP), data rate and receiver complexity are assessed. The results show that coded DTR is able to outperform conventional DTR receiver in terms of data rate maintaining the same BEP. Additionally, the receiver hardware complexity issue is discussed.

Keywords: coded differential TR (cDTR) receiver; IEEE 802.15.3a; inter-frame interference (IFI); ultra-wideband (UWB) system

\section{Ultra-širokopojasni sustav s ortogonalno kodiranim diferencijalnim TR prijemnikom}

Izvorni znanstveni članak

U ovom je radu predstavljen kodirani diferencijalni TR (cDTR) prijemnik koji mapiranjem informacije u $K$ različitih ortogonalnih kodova omogućuje prijenos dodatnog bita. Svojstva kodiranog DTR-a su analizirana i uspoređena s konvencionalnim DTR-om. Kroz analizu je dana ocjena svojstva prijemnika u smislu vjerojatnosti pogreške bita (BEP), brzine prijenosa i složenosti prijemnika. Rezultati su pokazali da kodirani DTR uz isti BEP omogućuje veću brzinu prijenosa od konvencionalnog DTR-a. Osim toga, razmotrena je i sklopovska složenost prijemnika.

Ključne riječi: IEEE 802.15.3a; interferencija između okvira (IFI); kodirani diferencijalni TR (cDTR) prijemnik; ultra-širokopojasni (UWB) sustav

\section{Introduction}

Ultra-wideband (UWB) technology has become a popular research topic in the field of wireless communications in recent years. This technology is also known by its other names such as carrier free radio, impulse radio and base-band radio. It is characterized by a huge potential in terms of throughput, performance and low cost implementation. Although UWB technology is not a new technology and despite its clear advantages, it was, until recently, partially unknown technology on the communication market. This is partly due to a fact that regulatory bodies restricted the use of the UWB to a limited number of applications which have been designed mainly for non-public (military) use. UWB system is based on the transmission of extremely narrow pulses $(<2$ ns) with a low average transmitted power ( $-41,3$ $\mathrm{dBm} / \mathrm{MHz}$ ). Due to short pulses used, UWB is capable to achieve high data rates (up to $1 \mathrm{Gbps}$ ) while its low power consumption enables coexistence with current radio technologies without interference and extending battery life at the same time, making UWB technology a very tempting solution for handheld devices.

One of the advantages of UWB communication is its ability to resolve individual multipath components [1] That poses a great challenge in front of researchers - how to efficiently capture the energy from all multipaths in order to maintain a sufficient output signal-to-noise ratio (SNR) $[2,3]$. In order to fully exploit the energy from all multipath components, the paper [4] proposes Rake receiver. At the Rake receiver, the channel estimation is required in order to demodulate the received signal which increases system complexity and system costs. In order to avoid the channel estimation required by the Rake receiver, a transmitted-reference (TR) receiver has been proposed in [5].

TR scheme uses two pulses which are transmitted in each frame, corresponding to the reference (unmodulated) and the data (modulated) pulse. Receiver in TR system correlates data pulse with a reference pulse where reference pulse is used as a template pulse. That enables avoiding channel estimation and allows a large amount of the received energy to be captured, despite distortion and multipath propagation. However, higher noise, lower data rate, as well as additional energy needed to transmit the reference pulse cause negative impact on TR system performance. Although lower system noise can be achieved by averaging several reference pulses prior to demodulation, as described in [6], communication resources are still wasted due to higher energy consumption (necessary for reference pulse transmission) and maximum data rate limitation (a consequence of inter-pulse-interference (IPI) cancelation procedure, i.e. distance between reference and data pulse).

A different approach to overcome all of the above mentioned disadvantages is based on the use of differential transmitted reference (DTR) receiver [7, 8]. DTR uses the concept of TR scheme without really transmitting reference pulse, but instead the delayed version of the previous frame is used as a reference $[8,9$, 10]. This concept leads to low-complexity receivers which are capable of capturing a large portion of the transmitted energy while communication resources, i.e. power and time, are more efficiently used, compared to the TR concept.

To improve DTR system performances, in terms of increased data rate, coded DTR scheme is proposed in this paper. Higher data rate is accomplished by mapping information in the frame level coding using $K$ orthogonal codes. To prove that the proposed coded DTR receiver outperforms the conventional DTR receiver, detail system analysis is presented. Transmission is simulated over typical UWB multipath channel model recommended by IEEE802.15.3. Simulation results show that proposed scheme increases data rate which makes bandwidth usage more efficient comparing to conventional DTR system. Although this paper deals only with the single user scenario, the multiple access techniques such as time- 
hoping or direct sequence can be used along with this method.

The paper is organized as follows. In Section 2, we describe our proposed coded DTR system model, UWB channel model and we make performance analysis for the proposed model. In Section 3 we present performance comparison between proposed and conventional DTR system. Concluding remarks are given in Section 4.

\section{Coded DTR system model}

\subsection{Transmitted signa}

In the conventional DTR transmitter, template waveform consists of a delay replica of a signal from previous frame. Therefore, information is defined as amplitude difference between two consecutive frames [8]. Structure of DTR transmitter is shown in Fig. 1. Transmitted signal of the $i$-th symbol in conventional DTR system can be written as

$s_{i}=\sqrt{\frac{E_{\mathrm{s}}}{N_{\mathrm{s}}}} \sum_{j=i N_{\mathrm{s}}}^{(i+1) N_{\mathrm{S}}-1} a_{j} p\left(t-j T_{\mathrm{f}}\right)$

where $E_{\mathrm{s}}$ is energy per symbol, $p(t)$ is the transmitted pulse waveform with duration $T_{\mathrm{p}}$ and unit energy, $\int_{-\infty}^{\infty} p^{2}(t) \mathrm{d} t=1$, while $T_{\mathrm{f}}$ denotes frame time. $\left.a_{j}=a_{j-1} b_{\frac{j}{N_{\mathrm{s}}}}\right]^{\text {is differentially encoded information }}$ symbol and $b_{\left[\frac{j}{N_{\mathrm{S}}}\right.} \in\{ \pm 1\}$ is the information bit in the $j$-th frame. The index $i=\left\lfloor j / N_{\mathrm{s}}\right\rfloor$ is the integer part of $j / N_{\mathrm{s}}$ and it represents the information of the $i$-th transmitted symbol. To achieve adequate symbol energy in the receiver and enable reliable detection, each symbol is transmitted in Ns successive frames, resulting with overall symbol duration time as $T_{\mathrm{s}}=N_{\mathrm{s}} T_{\mathrm{f}}$. Since DTR system does not require transmission of additional referent pulse, unlike the TR system, in order to avoid inter-frame interference (IFI) and inter-symbol interference (ISI), minimum $T_{\mathrm{f}}$ must be $T_{\mathrm{f}}=T_{\mathrm{p}}+T_{\mathrm{mds}}$, where $T_{\mathrm{mds}}$ represents channel delay spread [11].

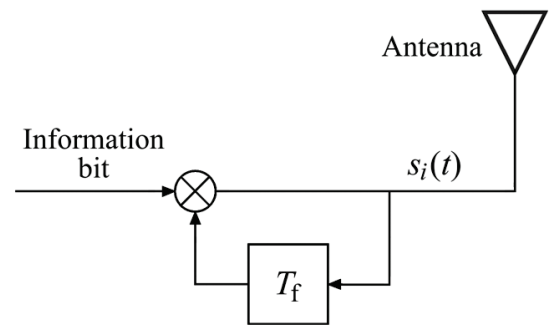

Figure 1 The structure of the DTR transmitter

In order to increase data rate and hence improve bandwidth efficiency, differentially encoded information symbol in proposed method is modified as

$$
a_{j}=a_{j-1}(-1)^{\left\lfloor\frac{j}{2^{k_{i}}}\right\rfloor}
$$

where $k_{i} \in\{0,1, \ldots, K-1\}$ determines the $i$-th symbol transmitted by unique orthogonal code where in order to achieve orthogonality between different codes over symbol period, $N_{s}=2^{K}$ must be set as a power of $2[12]$.

\subsection{Channel model}

During propagation between the transmitting and the receiving antenna, transmitted signal interacts with environment generating multipath components which are characterized by different arrival time and attenuation. Since UWB system is characterized by wide bandwidth (around 7,5 GHz), wireless channel will be highly frequency selective which means that signal at different frequencies experiences different attenuation and different delay. Consequently, standard channel models cannot be used for UWB system because they are only intended for narrowband systems where delay of multipath systems at receiver can be ignored.

Based on the measurements that have been made, IEEE 802.15.3a working group proposed a new discrete indoor wireless channel model for high data rate UWB communication. This channel model can be represented as

$h(t)=\sum_{l=1}^{L_{p}} \alpha_{l} \delta(t-l \Delta)$

where $L_{\mathrm{p}}$ is the total number of available multipath components, $\delta($.$) is the Dirac delta function and \alpha_{l}$ is the channel gain coefficient of the $l$-th time bin. In the $l$-th time bin $[l \Delta,(l+1) \Delta]$ one or more multipath components can arrive or cannot arrive at all. The channel gain coefficient of all arrived multipath components within that time bin is linear sum to yield a combined channel coefficient. Parameter $\Delta$ is chosen to be much less than $T_{\text {mds }}$ and it is set to $0,167 \mathrm{~ns}$, as suggested in [12], so that probability of pulse distortion will be greatly reduced. According to different propagation conditions, IEEE 802.15.3 a working group distinguishes four different channel models [13]:

- CM1: describes a line of sight (LOS) propagation with a separation between transmitter and receiver of less than $4 \mathrm{~m}$

- CM2: describes a none-line of sight (NLOS) propagation with a separation between transmitter and receiver of less than $4 \mathrm{~m}$

- CM3: describes a none-line of sight (NLOS) propagation with a separation between transmitter and receiver from $1 \mathrm{~m}$ to $10 \mathrm{~m}$

- CM4: describes an environment with strong delay dispersion.

In this work a discrete channel model CM1 and CM3 is used since CM1 and CM2 as well as CM3 and CM4 have similar channel delay spread [14].

\subsection{Performance of a coded DTR receiver}

In a single user scenario the received signal of DTR system after passing through the UWB channel in the presence of multipath and noise is given by 
$r(t)=s_{i}(t) \otimes h(t)+n(t)=\sqrt{\frac{E_{\mathrm{s}}}{N_{\mathrm{s}}}} \sum_{j=i N_{\mathrm{S}}}^{(i+1) N_{\mathrm{S}}-1} a_{j} g\left(t-j T_{\mathrm{f}}\right)+n(t)$,

where $g(t)=p(t) \otimes h(t)=\sum_{l=1}^{L_{\mathrm{p}}} \alpha_{l} p(t-l \Delta)$ is the received waveform, $\otimes$ denotes the convolution and $n(t)$ is the additive white Gaussian noise with mean zero and power spectrum density of $N_{0} / 2$.

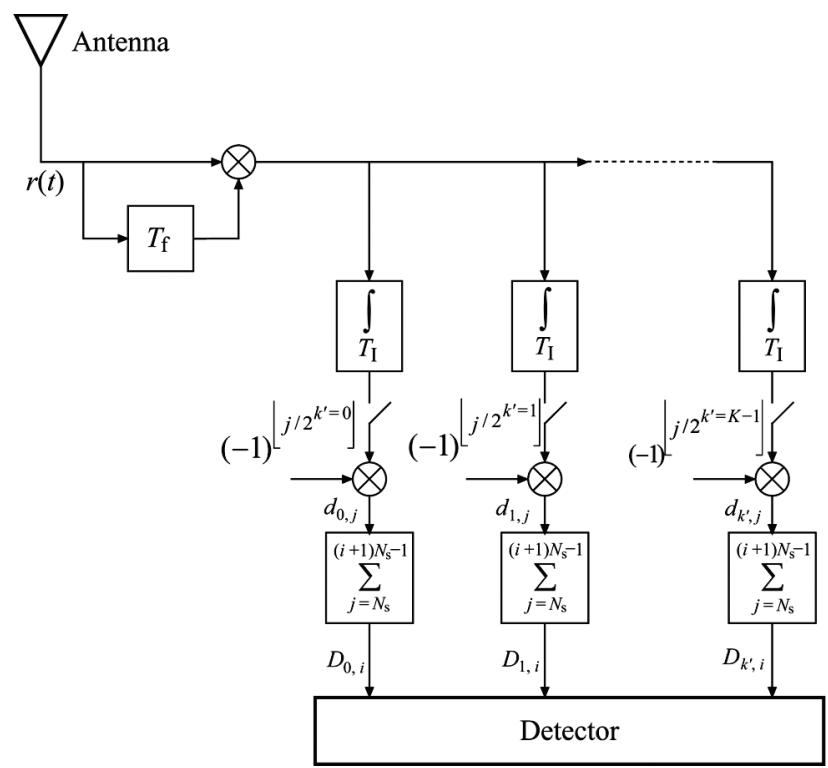

Figure 2 The structure of coded DTR receiver

The receiver firstly correlates each frame with the previous one and then integrates product in the interval

$T_{I}=\left(j T_{\mathrm{f}}, j T_{\mathrm{f}}+T_{\text {corr }}\right)$,

where $T_{\text {corr }}$ is assumed to be an integer multiple of the pulse width, denoted as $T_{\text {corr }}=L_{\text {corr }} T_{\mathrm{p}}$, where $L_{\text {corr }} \in\left\{1,2, \ldots, L_{\mathrm{p}}\right\}$. The integration interval $T_{\mathrm{I}}$ determines the number of multipath components (the amount of energy) as well as the amount of noise captured by the receiver.

Result of integration is then multiplied by one of the $(-1)^{\left\lfloor j / 2^{k^{\prime}}\right\rfloor}$ orthogonal codes, as it is shown in Fig. 2, where parameter $k^{\prime}$ defines the unique orthogonal code at the receiver side and it is defined as $k^{\prime} \in\{0,1, \ldots K-1\}$. Depending on the chosen $k^{\prime}$ results of multiplication will be

$$
\begin{gathered}
\sum_{j=i N_{\mathrm{S}}}^{(i+1) N_{\mathrm{S}}-1}(-1)^{\left\lfloor\frac{j}{2^{k_{i}}}\right\rfloor}(-1)^{\left\lfloor\frac{j}{2^{k^{\prime}}}\right\rfloor}=0, \text { for } k_{i} \neq k^{\prime} \\
\sum_{j=i N_{\mathrm{S}}}^{(i+1) N_{\mathrm{S}}-1}(-1)^{\left\lfloor\frac{j}{2^{k_{i}}}\right\rfloor}{ }_{(-1)^{\lfloor}\left\lfloor\frac{j}{2^{k^{\prime}}}\right\rfloor}=N_{\mathrm{s}}, \text { for } k_{i}=k^{\prime} .
\end{gathered}
$$

In the $j$-th symbol, the correlation output of the $k^{\prime}$-th code at the receiver is

$$
d_{k^{\prime}, j}=(-1)^{\left\lfloor\frac{j}{2^{k^{\prime}}}\right\rfloor} \int_{T_{\mathrm{I}}} r_{j}(t) r_{j-1}\left(t-T_{\mathrm{f}}\right) \mathrm{d} t
$$

DTR transceiver symbol structure, when information is mapped in the $\{1,-1,1,-1\}$ orthogonal code, as well as process for determining transmitted symbol in coded DTR receiver is shown in Fig. 3. Fig. 3a shows that desired signal in decision variable will be nonzero only if orthogonal code in the receiver is the same as the one in the transmitter $\left(k_{i}=k^{\prime}\right)$, otherwise desired signal will be zero, as shown in Fig. 3b. Finally, code at the final output with the largest magnitude is chosen as the one which was transmitted.

The decision variable for the $k^{\prime}$-th code and the $i$-th symbol can be written as

$$
\begin{aligned}
& D_{k^{\prime}, i}=\sum_{j=i N_{\mathrm{s}}}^{(i+1) N_{\mathrm{s}}-1} d_{k^{\prime}, j}=\varepsilon_{k^{\prime}, i}+N_{k^{\prime}, i, 1}+N_{k^{\prime}, i, 2}+N_{k^{\prime}, i, 3}= \\
& =\frac{E_{\mathrm{s}}}{N_{\mathrm{s}}} \sum_{j=N_{\mathrm{s}}}^{(i+1) N_{\mathrm{s}}-1} a_{j} a_{j-1} \int_{j T_{\mathrm{f}}}^{j T_{\mathrm{f}}+T_{\mathrm{corr}}} g^{2}(t) \mathrm{d} t+N_{k^{\prime}, i, 1}+N_{k^{\prime}, i, 2}+N_{k^{\prime}, i, 3},
\end{aligned}
$$

where term $\varepsilon_{k^{\prime}, j}$ denotes desired signal, $N_{k^{\prime}, i, 1}$ and $N_{k^{\prime}, i, 2}$ are due to signal $\times$ noise component and $N_{k^{\prime}, i, 3}$ is the noise $\times$ noise component.

According to (6) and (7), (9) can be rewritten as

$$
D_{k^{\prime}, i}=\left\{\begin{array}{cc}
\varepsilon_{k^{\prime}, i}+N_{k^{\prime}, i, 1}+N_{k^{\prime}, i, 2}+N_{k^{\prime}, i, 3} & \text { for } k_{i}=k^{\prime} \\
N_{k^{\prime}, i, 1}+N_{k^{\prime}, i, 2}+N_{k^{\prime}, i, 3} & \text { for } k_{i} \neq k^{\prime}
\end{array} .\right.
$$

The mean value of the desired signal can be written as

$$
E\left(\varepsilon_{k^{\prime}, i}\right)= \begin{cases}E_{\mathrm{s}} a_{j} a_{j-1} \sum_{l=1}^{L_{\mathrm{corr}}} E\left(\alpha_{l}^{2}\right) \int_{0}^{T_{\mathrm{p}}} p^{2}(t) \mathrm{d} t, & \text { for } k_{i}=k^{\prime}, \\ 0, & \text { for } k_{i} \neq k^{\prime}\end{cases}
$$

where $E\left(\alpha_{l}^{2}\right)$ is mean energy of the l-th multipath component energy and overall channel energy is normalized to be $\sum_{l=1}^{L_{\mathrm{p}}} E\left(\alpha_{l}^{2}\right)=1 . N_{k^{\prime}, i, 1}, N_{k^{\prime}, i, 2}$ and $N_{k^{\prime}, i, 3}$ components are assumed that they are Gaussian random variables whose variables are respectively

$$
\begin{aligned}
& \operatorname{var}\left(N_{k^{\prime}, i, 1}\right)=E\left(N_{k^{\prime}, i, 1}^{2}\right)= \\
& =E\left\{\left[\sum_{j=i N_{\mathrm{s}}}^{(i+1) N_{\mathrm{s}}-1}\left[\sqrt{\frac{E_{\mathrm{s}}}{N_{\mathrm{s}}}} a_{j-1} \int_{j T_{\mathrm{f}}}^{j T_{\mathrm{f}}+T_{\mathrm{corr}}} g\left(t-j T_{\mathrm{f}}\right) n(t) \mathrm{d} t\right)\right]^{2}\right\}= \\
& =\frac{N_{0} E_{\mathrm{s}}}{2}\left(\sum_{l=1}^{L_{\mathrm{corr}}} E\left(\alpha_{l}^{2}\right) \int_{0}^{T_{\mathrm{p}}} p^{2}(t) \mathrm{d} t\right)
\end{aligned}
$$




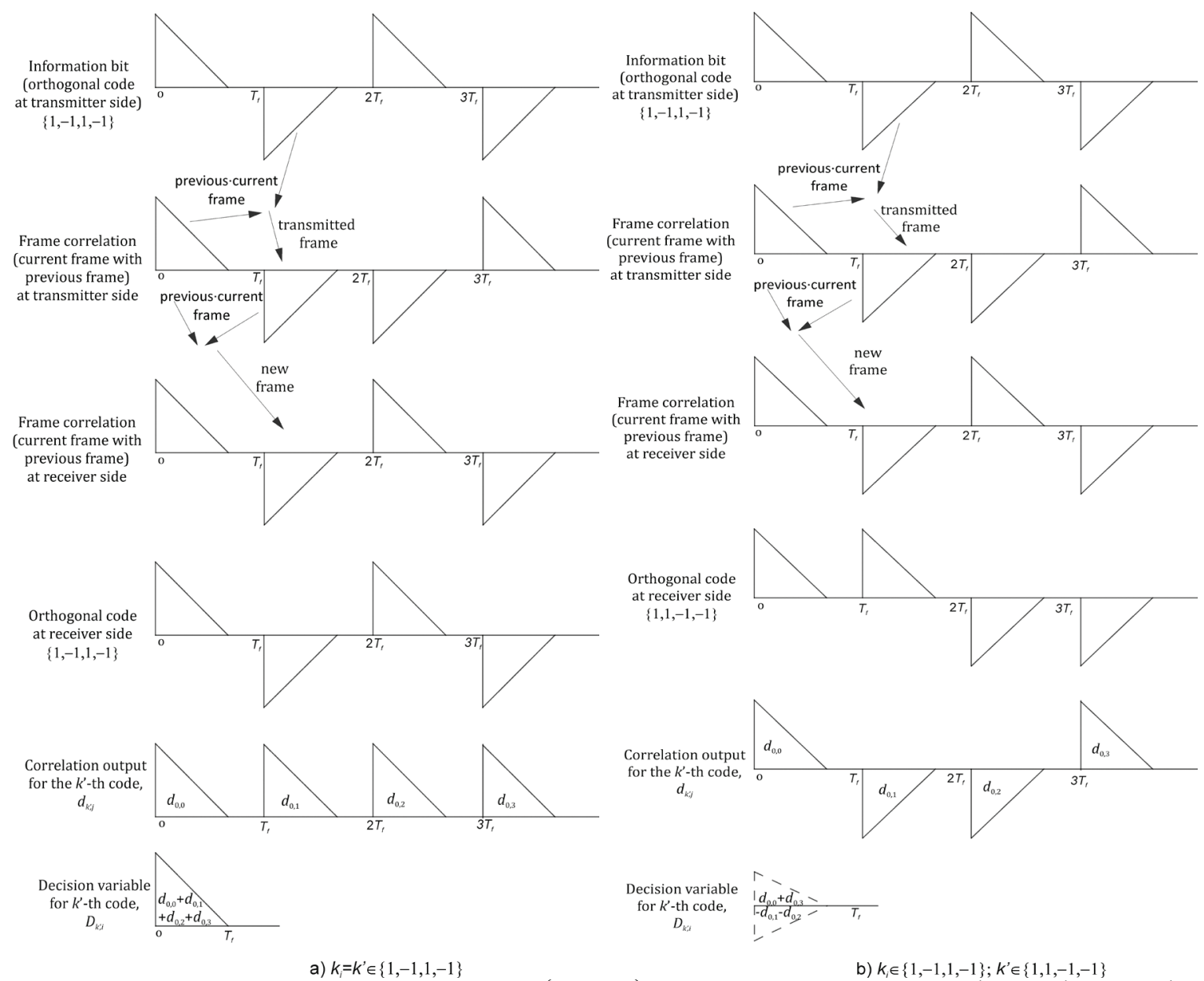

Figure 3 Coded DTR transceiver symbol structure when a) $k_{i}=k^{\prime} \in\{1,-1,1,-1\}$ orthogonal code is used and b) $k_{i} \in\{1,-1,1,-1\}$ and $k^{\prime} \in\{1,1,-1,-1\}$ orthogonal code is used

$\operatorname{var}\left(N_{k^{\prime}, i, 2}\right)=E\left(N_{k^{\prime}, i, 2}^{2}\right)=$

$=E\left\{\left[\sum_{j=i N_{\mathrm{s}}}^{(i+1) N_{\mathrm{s}^{-1}}}\left(\sqrt{\frac{E_{\mathrm{s}}}{N_{\mathrm{s}}}} a_{j} \int_{j T_{\mathrm{f}}}^{j T_{\mathrm{f}}+T_{\mathrm{corr}}} g\left(t-j T_{\mathrm{f}}\right) n\left(t-T_{\mathrm{f}}\right) d t\right)\right]^{2}\right\}=$

$=\frac{N_{0} E_{\mathrm{s}}}{2}\left(\sum_{l=1}^{L_{\text {corr }}} E\left(\alpha_{l}^{2}\right) \int_{0}^{T_{\mathrm{p}}} p^{2}(t) \mathrm{d} t\right)$,

$\operatorname{var}\left(N_{k^{\prime}, i, 3}\right)=\frac{N_{\mathrm{s}} N_{0}{ }^{2} W T_{\text {corr }}}{2}$,

where $W$ is the receiver's front-end filter bandwidth.

As it is shown in Fig. 2, after demodulation the detector processes $K$ correlator outputs and selects the correlator with the highest value. Using the techniques described in [15], the probability of the correct decision for the $i$-th symbol when the $k_{i}$-th code is transmitted can be calculated as

$P_{c, i}=\frac{1}{K} \sum_{k_{i}=0}^{K-1} \int_{-\infty}^{\infty}\left(\prod_{\substack{k^{\prime}=0, \\ \text { if } k^{\prime} \neq k_{i}}}^{K-1} \frac{1}{\sqrt{2 \pi}} \times\right.$

$\left.\times \quad \int_{-\infty}^{D_{0, k^{\prime}=k_{i}, i} / \sqrt{\operatorname{var}_{\text {tot }, k^{\prime}, i}}} \exp \left(-\frac{x^{2}}{2}\right) \mathrm{d} x\right) p\left(D_{k^{\prime}=k_{i}, i}\right) \mathrm{d} D_{k^{\prime}=k_{i}, i}$, where $p\left(D_{k^{\prime}=k_{i}, i}\right) \quad$ is the probability density function (PDF) of the first correlation output for the $i$-th symbol when the $k_{i}$-th code is transmitted

$$
p\left(D_{k^{\prime}=k_{i}, i}\right)=\frac{1}{\sqrt{2 \pi \operatorname{var}_{\mathrm{tot}, k^{\prime}=k_{i}, i}}} \exp \left(\frac{\left(D_{k^{\prime}=k_{i}, i}-E\left(\varepsilon_{k^{\prime}, i}\right)\right)^{2}}{2 \operatorname{var}_{\mathrm{tot}, k^{\prime}=k_{i}, i}}\right),
$$

where $\operatorname{var}_{\text {tot }, k^{\prime}=k_{i}, i}$ is the sum of all variances of the $i$-th symbol at the $\left(k^{\prime}=k_{i}\right)$ correlator output. Finally, the probability of symbol error can be calculated as

$P_{\mathrm{M}}=1-P_{\mathrm{c}}$,

while, according to [15], bit error probability (BEP) can be written as

$P_{b}=\frac{2^{b-1}}{2^{b}-1} P_{\mathrm{M}}$,

where $b$ denotes the number of bits per symbol and it is defined as $b=\log _{2}(K)$. 


\section{Results and discussion}

In this section, simulation results of the proposed coded DTR receiver are presented in order to validate the performance (BEP) and theoretical framework developed in the previous sections. BEP performance and data rate are simulated over typical CM1 UWB multipath channel model which is recommended by IEEE802.15.3a. In order to verify the system performance in NLOS scenario data rate is additionally analyzed for CM3 channel model. In order to capture most of the signal energy, channel delay spread is set to 200 time bins for CM1 $\left(T_{\mathrm{mds}}=33,4 \mathrm{~ns}\right)$ and 400 time bins for CM3 $\left(T_{\mathrm{mds}}=66,8 \mathrm{~ns}\right)$, as suggested in [14]. Frame time $T_{\mathrm{f}}$ is set to $T_{\mathrm{f}}=T_{\mathrm{p}}+T_{\mathrm{mds}}$ which is large enough to prevent IFI and ISI, as suggested in $[11,16]$. The arrival time axis of the multipath components is divided into small time bins of 0,167 ns and transmitted energy is normalized to $E_{\mathrm{s}}=1$. Receiver filter has onesided bandwidth $W=6 \mathrm{GHz}$ and we assumed that the desired signal passes through the filter without energy loss.

To get the best system performances in a sense of BEP, integration interval $T_{\mathrm{I}}$, defined in (5), should be set to value where BEP will be minimal, what is known as optimal integration interval, $T_{\mathrm{I} \text { opt }}$. In order to find an optimal integration interval, BEP versus $T_{\mathrm{I}}$ is plotted in Fig. 4 for $N_{\mathrm{s}}=4$ and energy per bit to noise power ratio $E_{b} / N_{0}=20 \mathrm{~dB}$, where $E_{b}$ denotes transmitted energy per bit and it is given as $E_{b}=E_{\mathrm{s}} / \log _{2}(K)$.

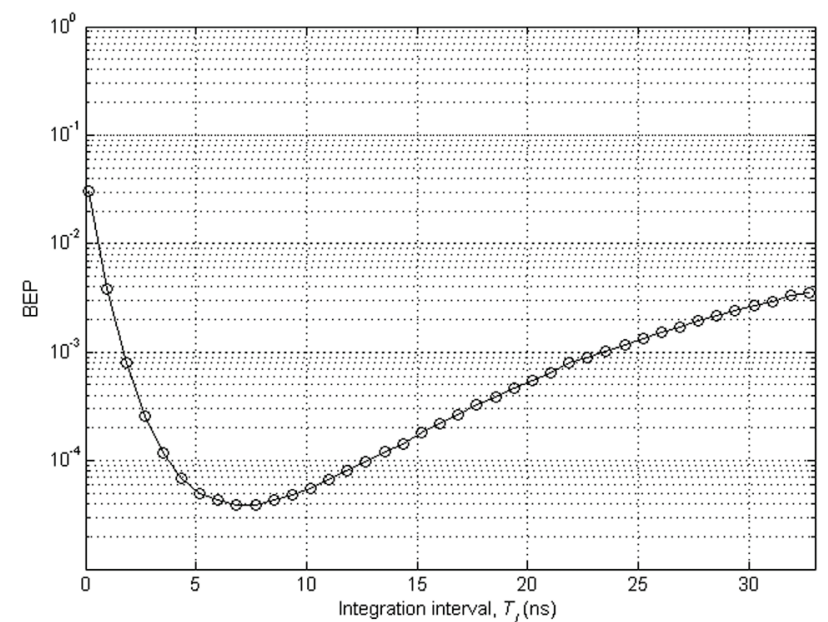

Figure 4 BEP versus integration interval when $E_{b} / N_{0}=20 \mathrm{~dB}$ and $N_{\mathrm{s}}=4$

Fig. 4 shows that BEP reaches its minimum around $T_{\text {I opt }}=7 \mathrm{~ns}$. For $T_{\mathrm{I}}>T_{\mathrm{I} \text { opt }}$, the contribution of the noise component (12), (13) and (14) significantly dominates over desired signal energy, resulting with system performance degradation. Therefore, the integration interval should be large enough to capture sufficient energy of received signal, and at the same time it should be as small as possible so it does not accumulate too much noise.

The BEP versus $E_{b} / N_{0}$ of the conventional DTR and coded DTR receiver structures are plotted in Fig. 5. In order to compare performances of these two receivers, analysis results of conventional DTR receiver for single user scenario presented in [16] for $N_{\mathrm{s}}=4$ are used.

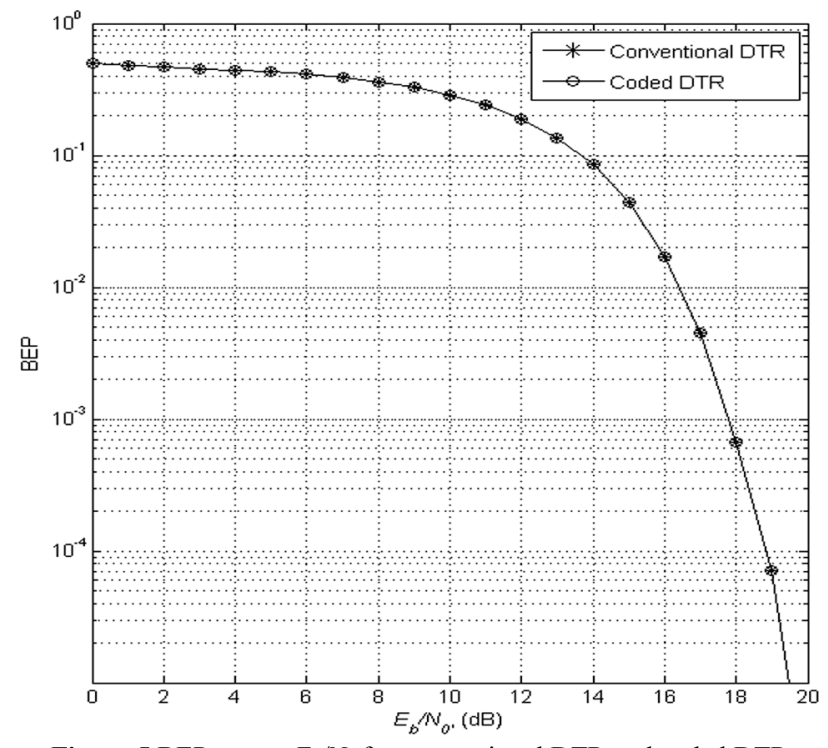

Figure 5 BEP versus $E_{b} / N_{0}$ for conventional DTR and coded DTR when $N_{\mathrm{s}}=4$

Fig. 5 shows that proposed coded DTR receiver has the same BEP performance as the conventional DTR receiver. This is an important result since it verifies that coded DTR, in terms of BEP, can be good replacement for conventional DTR. It also shows that BEP performance of both DTR receivers improves evidently when $E_{b} / N_{0}$ increases. This improvement in BEP is the result of decreasing the impact of noise on the performance of the receivers when $E_{b} / N_{0}$ increases.

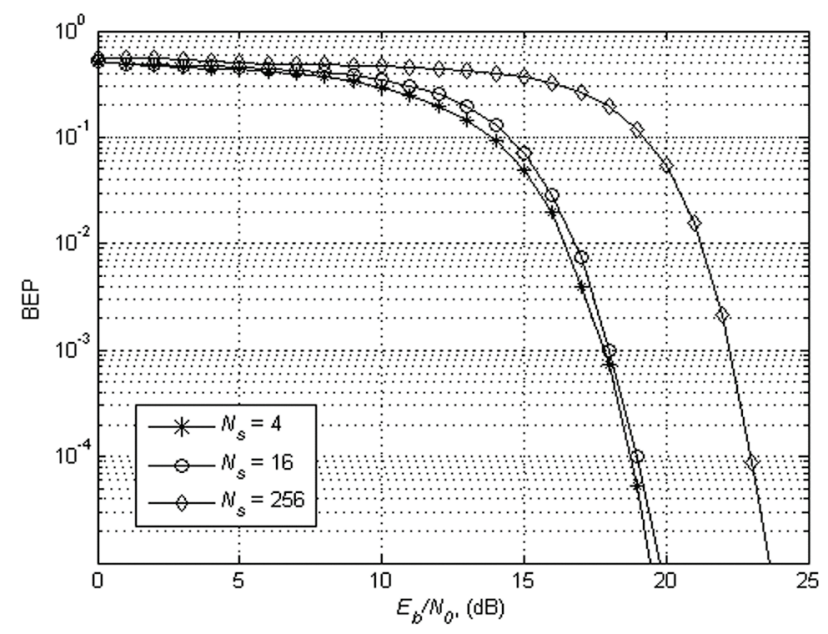

Figure $6 \mathrm{BEP}$ versus $E_{b} / N_{0}$ for coded DTR for different number of frames per symbol $N_{\mathrm{s}}$

In Fig. 6 the performance of coded DTR receiver for different number of frames $N_{s}$ is shown. It can be seen that BEP significantly increases with greater number of frames, $N_{\mathrm{s}}$, e.g. for $N_{\mathrm{s}}=4$ and $E_{b} / N_{0}=19 \mathrm{~dB}, \mathrm{BEP}$ is around $10^{-4,3}$ while for the same $E_{b} / N_{0}$ and for $N_{\mathrm{s}}=256$, $\mathrm{BEP}$ is around $10^{-1}$. This BEP performance degradation is due to more noise that is received by the receiver as it is shown in (14). For the fixed BEP of $10^{-4}$, it can be seen that around $1 \mathrm{~dB}$ higher $E_{b} / N_{0}$ is required for $N_{\mathrm{s}}=16(K=$ $4, b=2)$ is used instead of $N_{\mathrm{s}}=4(K=2, b=1)$. This increase in $E_{b} / N_{0}$ is quite low in comparison to the increase achieved in bandwidth efficiency, i.e. data rate is double increased. The data rate for the same BEP 
performance can be additionally increased by using higher $E_{b} / N_{0}$ and higher $N_{\mathrm{s}}$.

Fig. 7 shows the comparison of conventional DTR and coded DTR receiver in respect to the achievable data rate for different $N_{s}$ in $\mathrm{CM} 1$, apropos CM3 channel model.

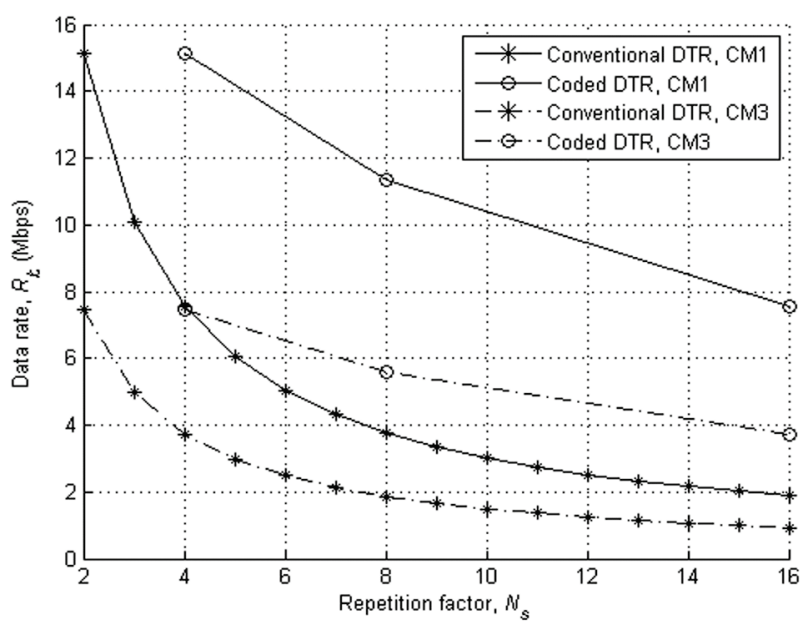

Figure 7 Data rate versus repetition factor for conventional DTR and coded DTR and channel models CM1 and CM3

Coded DTR for the same $N_{s}$ has achieved higher data rate than conventional DTR in both channel models, as it can be seen from figure. That is due to the extra bits that are transmitted by frame level coding of signal using the $K$ possible orthogonal codes, e.g. when $N_{\mathrm{s}}=16(K=4)$ and CM1 is used, coded DTR has achieved data rate of 7,5 Mbps while for the same channel model and same $N_{s}$ data rate for conventional DTR is 1,9 Mbps. The achievable bit rate for a given $N_{s}$ decreases in CM3 due to the increase of channel delay spread. Taking into account results presented in this section, it is evident that coded DTR receiver outperforms conventional DTR, since higher data rate can be accomplished (Fig. 7) for the same BEP performance (Fig. 5). Achieving higher data rate, however, comes at a cost of higher receiver complexity. Although receiver structure of coded DTR receiver is increased, it is still simple as well as implementable and it improves receiver performances.

\section{Conclusion}

Coded DTR receiver performance study has been carried out in this research. $K$ orthogonal codes are used to transmit extra bit in the proposed method. In order to analyze system performance of proposed receiver, BEP has been analyzed over CM1 channel model while data rate has been additionally analyzed over CM3 channel model. Results were compared with conventional DTR system. It has been shown that coded DTR receiver achieves the same BEP performance as conventional DTR receiver. It was also shown that the proposed system can be used to transmit higher data rate than the conventional DTR. This increase in data rate comes along with increased system complexity due to more orthogonal codes that has to be transmitted. Succeeding papers will be focused on the different techniques intended to reduce system complexity.

\section{$5 \quad$ References}

[1] Carnbonelli, C.; Mengali, U. Synchronization algorithms for UWB signals. // IEEE Trans. Commun. 54, 2(2006), pp. 329-338. DOI: 10.1109/TCOMM.2005.863728

[2] Forester, J. R. The effects of multipath interference on the performance of UWB systems in an indoor wireless channel. // Proc. of the Veh. Technol. Conf., May 2001, pp. 1176-1180. DOI: 10.1109/vetecs.2001.944566

[3] Win, M. Z.; Scholtz, R. A. On the energy capture of ultrawide bandwidth signals in dense multipath environments. // IEEE Commun. Lett. 2, 9(1998), pp. 245247. DOI: $10.1109 / 4234.718491$

[4] Win, M. Z.; Scholtz, R. A. Characterization of ultra-wide bandwidth wireless communications channels: A communication theoretic view. // IEEE J. Sel. Areas Commun. 20, 9(2002), pp. 1613-1627. DOI: 10.1109/JSAC.2002.805031

[5] Hoctor, R.; Tomlinson, H. Delay-hopped transmittedreference RF communications. // Proc. of the IEEE UWBST, May 2002, pp. 265-269. DOI: 10.1109/uwbst.2002.1006368

[6] Choi, D. J.; Stark, W. E. Performance of ultra-wideband communications with suboptimal receivers in multipath channels. // IEEE J. Sel. Areas Commun. 20, 9(2002), pp. 1754-1766. DOI: 10.1109/JSAC.2002.805623

[7] Durisi, G.; Benedetto, S. Comparison between coherent and noncoherent receivers for UWB communications. // EURASIP Jurnal on Wireless Comm. and Networking, 2005.

[8] Chao, Y. L.; Scholtz, R. A. Optimal and suboptimal receiver for ultra-wideband transmitted reference systems. // Proc. of the IEEE GLOBECOM, Dec. 2003, pp. 759-763.

[9] Hazra, R.; Tyagi, A.; Mukherjee, S. Performance analysis of TR, ATR and DTR receivers in IR-UWB communication system. // Proc. of the IEEE ICSPCC, Aug. 2013, pp. 1-6. DOI: 10.1109/icspcc.2013.6663934

[10] Zhou, Q.; Ma. Q. Receiver design for UWB differential transmitted reference systems with multiple access interference. // Proc. of the IEEE ICUWB, Sept. 2011, pp. 205-209.

[11] Li. L.; Townsend, J. K.; Ulman, R. J. Multiple-access performance of transmitted reference UWB communications with M-ary PPM. // Proc. of the IEEE GLOBECOM, Nov. 2008. pp. 1-6. DOI: 10.1109/glocom.2008.ecp.752

[12] Kim, D. I.; Tao, J. M-ary orthogonal coded/balanced ultrawideband transmitted-reference systems in multipath. // IEEE Trans. Commun. 56, 1(2008), pp. 102-111. DOI: 10.1109/TCOMM.2008.050310

[13] Molisch, A. F.; Foerster, J. R.; Pendergrass, M. Channel models for ultrawideband personal area networks. // IEEE Wireless Commun. 10, 6(2003), pp. 14-21. DOI: 10.1109/MWC.2003.1265848

[14] Tao J.; Dong. I. K. Analysis of channel-averaged SINR for indoor UWB rake and transmitted reference systems. // IEEE Trans. Commun. 55, 10(2007), pp. 2022-2032. DOI: 10.1109/TCOMM.2007.906435

[15] Proaksis, J. G. Digital Communications, $4^{\text {th }}$ ed. McGrawHill, New York, 2001.

[16] Chao, Y. L.; Scholtz, R. A. Multiple access performance of ultra-wideband transmitted reference systems in multipath environments. // Proc. of the IEEE WCNC, Mar. 2004, pp. 1788-1793. 


\section{Authors' addresses}

mr. sc. Josip Milanović

Croatian regulatory authority for network industries

R. F. Mihanovića 9, Zagreb, Croatia

E-mail: josip.milanovic@hakom.hr

Prof. dr. sc. Snježana Rimac-Drlje

J. J. Strossmayer University of Osijek,

Faculty of Electrical Engineering,

Kneza Trpimira 2B, Osijek, Croatia

E-mail: snjezana.rimac@etfos.hr

Doc. dr. sc. Slavko Rupčić

J. J. Strossmayer University of Osijek,

Faculty of Electrical Engineering

Kneza Trpimira 2B, Osijek, Croatia

E-mail: slavko.rupcic@etfos.hr 